\title{
Audit of operational noise at the leicester royal infirmary aicu
}

\author{
M Charlton ${ }^{1 *}$, KA Prosho $^{2}, \mathrm{D}^{\prime} \mathrm{Neil}^{1}$ \\ From ESICM LIVES 2015 \\ Berlin, Germany. 3-7 October 2015
}

\section{Introduction}

Ambient noise and its impact on sleep is an important factor in the development of delirium [1]. Noise is a problem on intensive care units, being one of the main environmental stress inducing factors amongst patients [2]. A key source of noise is the signalling of alarms.

As part of plans to decrease noise, we investigated the number and appropriateness of alarms sounded overnight. An initial audit demonstrated that over 53\% of alarms were inappropriate, with two recurring sources being due to sampling from indwelling lines and physiological variables falling outside of a pre-programmed range.

Following this we implemented a brief educational programme, highlighting the importance of setting appropriate alarm limits and muting prior to sampling from lines. We then re-audited to determine if improvement had been made.

\section{Objectives}

Improvement in the frequency of inappropriately sounded alarms at night following intervention.

Audit standard: $90 \%$ of alarms being deemed as appropriate.

\section{Methods}

Data was collected prospectively by nursing staff on the intensive care unit. Nurses were allocated to collect data on a bed-space other than their own to reduce bias. Data collected included the source and response to the alarm. Data was reviewed by the authors to determine if the alarms and response were appropriate.

'Leicester Royal Infirmary, Department of Anaesthesia and Critical Care,

Leicester, United Kingdom

Full list of author information is available at the end of the article

\section{Results}

Data was collected over 7 nights with the total number of recorded alarms being 200. Alarm sources included patient monitoring, infusion pumps and ventilators amongst others. $39 \%$ of the alarms were deemed to be inappropriate with $7.7 \%$ of these being due to sampling from arterial lines. Other frequently occurring alarms included physiological variables and minute/tidal volumes falling outside of pre-determined ranges (34.6\% and $15.4 \%$ respectively).

\section{Conclusions}

Compared to the first audit, the number of alarms deemed as inappropriate has reduced from $53.9 \%$ to $39 \%$. Alarms due to sampling from indwelling lines have reduced from $20.8 \%$ to $7.7 \%$. Alarms due to physiological variables falling outside of the pre-determined ranges have increased from $27.1 \%$ to $34.6 \%$.

Ensuring quality sleep forms an integral part of a patient's recovery from critical illness and its lack thereof plays an important role in the development of delirium with its subsequent effects on morbidity and mortality. Excess ambient noise due to inappropriate alarms will impact on sleep.

Despite some improvement, we have failed to meet our self-imposed audit standard. We plan to reaffirm the muting of alarms prior to taking blood samples and reinforce the importance of appropriate setting of physiological variable limits at the start of each clinical shift. We plan to implement a daily checklist to ensure this is complete.

\footnotetext{
Authors' details

'Leicester Royal Infirmary, Department of Anaesthesia and Critical Care, Leicester, United Kingdom. ${ }^{2}$ Leicester Royal Infirmary, Adult Intensive Care Unit, Leicester, United Kingdom.
}

(c) 2015 Charlton et al.; This is an Open Access article distributed under the terms of the Creative Commons Attribution License (http:// creativecommons.org/licenses/by/4.0), which permits unrestricted use, distribution, and reproduction in any medium, provided the original work is properly cited. 
Published: 1 October 2015

\section{References}

1. Schiemann A, Hadzidiakos D, Spies C: Managing ICU delirium. Curr Opin Crit Care 2011, 12:131-40.

2. Cornock MA: Stress and the intensive care patient: perceptions of patients and nurses. J Adv Nurs 1998, 27(3):518-27, Mar.

doi:10.1186/2197-425X-3-S1-A146

Cite this article as: Charlton et al: Audit of operational noise at the leicester royal infirmary aicu. Intensive Care Medicine Experimental 20153 (Suppl 1):A146.

\section{Submit your manuscript to a SpringerOpen ${ }^{\mathcal{O}}$ journal and benefit from:}

- Convenient online submission

- Rigorous peer review

- Immediate publication on acceptance

- Open access: articles freely available online

- High visibility within the field

- Retaining the copyright to your article

Submit your next manuscript at $>$ springeropen.com 